\title{
System Wide Analyses have Underestimated Protein Abundances and the Importance of Transcription in Mammals
}

Large scale surveys in mammalian tissue culture cells suggest that the protein expressed at the median abundance is present at 8,000-16,000 molecules per cell and that differences in mRNA expression between genes explain only $10-40 \%$ of the differences in protein levels. We find, however, that these surveys have significantly underestimated protein abundances and the relative importance of transcription. Using individual measurements for 61 housekeeping proteins to rescale whole proteome data from Schwanhausser et al., we find that the median protein detected is expressed at 170,000 molecules per cell and that our corrected protein abundance estimates show a higher correlation with mRNA abundances than do the uncorrected protein data. In addition, we estimated the impact of further errors in mRNA and protein abundances using direct experimental measurements of these errors. The resulting analysis suggests that mRNA levels explain at least $56 \%$ of the differences in protein abundance for the 4,212 genes detected by Schwanhausser et al., though because one major source of error could not be estimated the true percent contribution could be higher. We also employed a second, independent strategy to determine the contribution of mRNA levels to protein expression. We show that the variance in translation rates directly measured by ribosome profiling is only $12 \%$ of that inferred by Schwanhausser et al. and that the measured and inferred translation rates correlate only poorly $\left(R^{2}=0.13\right)$. Based on this, our second strategy suggests that mRNA levels explain $\sim 81 \%$ of the variance in protein levels. We also determine the percent contributions of transcription, RNA degradation, translation and protein degradation to the variance in protein abundances using both of our strategies. While the magnitudes of the two estimates vary, they both suggest that transcription plays a more important role than the earlier studies implied and translation a much smaller role. Finally, the above estimates only apply to those genes whose mRNA and protein expression was detected. Based on a detailed analysis by Hebenstreit et al., we 
estimate that approximately $40 \%$ of genes in a given cell within a population express no mRNA. Since there can be no translation in the absence of mRNA, we argue that differences in translation rates can play no role in determining the expression levels for the $\sim 40 \%$ of genes that are non-expressed. 
1 Jingyi Jessica Li, Department of Statistics, University of California, Berkeley CA USA ${ }^{1}$

2 Peter J. Bickel, Department of Statistics, University of California, Berkeley CA USA

3 Mark D. Biggin, Genomics Division, Lawrence Berkeley National Laboratory, Berkeley CA USA

4

5 Corresponding author:

6 Mark D. Biggin

+7 Genomics Division

든 8 Lawrence Berkeley National Laboratory

@ 91 Cyclotron Road MS 84-171

$\subsetneq 10 \quad$ Berkeley CA 94720.

$\sum^{\infty} 11$

1.2 email mdbiggin@lbl.gov

-13 phone 5104867606

$>14$

$-15$

${ }^{1}$ current address Department of Statistics, University of California, Los Angeles CA USA $\Upsilon 17$ 


\section{INTRODUCTION}

18 The protein products of genes are expressed at very different levels from each other in a 19 mammalian cell. Thousands of genes are not detectably expressed. Of those that are, their 20 proteins are present at levels that differ by five orders of magnitude. Cytoplasmic actin, for 21 example, is expressed at $1.5 \times 10^{8}$ molecules per cell (Kislauskis et al. 1997), whereas some 22 transcription factors are expressed at only $4 \times 10^{3}$ molecules per cell (Biggin 2011). There are four major steps that determine differences in protein expression: the rates at which genes are transcribed, mRNAs are degraded, proteins are translated, and proteins are degraded (Fig. 1). The combined effect of transcription and mRNA degradation together determines mRNA abundances (Fig. 1). The joint effect of protein translation and protein degradation controls the relative differences between mRNA and protein concentrations (Fig. 1).

Transcription has long been regarded as a dominant step and is controlled by sequence specific transcription factors that differentially interact with cis-regulatory DNA regions. The rates of the other three steps, however, vary significantly between genes as well (Boisvert et al. 2012; Cambridge et al. 2011; Cheadle et al. 2005; de Sousa Abreu et al. 2009; Eden et al. 2011; Guo et al. 2010; Han et al. 2013; Hentze \& Kuhn 1996; Hsieh et al. 2012; Ingolia et al. 2011; Kristensen et al. 2013; Loriaux \& Hoffmann 2013; Rabani et al. 2011; Schwanhausser et al. 2011; Sharova et al. 2009; Yang et al. 2003). MicroRNAs, for example, differentially interact with mRNAs to alter rates of RNA degradation and protein translation (Ambros 2011; Baek et al. 2008; Elmen et al. 2008; Gennarino et al. 2012; Guo et al. 2010; Hobert 2008; Krutzfeldt et al. 2005; Pillai et al. 2007; Rajewsky 2011; Selbach et al. 2008; Subtelny et al. 2013; Xiao et al. 38 2007).

To quantify the relative importance of each of the four steps, label free mass spectrometry methods have been developed that measure the absolute number of protein molecules expressed per cell for thousands of genes (Bantscheff et al. 2012; Beck et al. 2011; Maier et al. 2009; Schwanhausser et al. 2011; Vogel et al. 2010; Vogel \& Marcotte 2012). By comparing these data to mRNA abundance data, the relative importance of transcription and mRNA degradation versus protein translation and protein degradation can be determined (Maier et al. 2009; Schwanhausser et al. 2011; Vogel \& Marcotte 2012) (Fig. 1). By measuring mRNA degradation and protein degradation rates as well, the rates of transcription and translation can be additionally inferred indirectly. Using this approach to study mouse NIH3T3 fibroblasts, Schwanhausser et al. concluded that mRNA levels explain $\sim 40 \%$ of the variability in protein levels; that the cellular abundance of proteins is predominantly controlled at the level of 
translation; that transcription is the second largest determinant; and that the degradation of mRNAs and proteins play a significant but lesser role (Schwanhausser et al. 2011).

52 The above work has provided critically important datasets and an initial framework for analysis.

53 We noticed, however, that Schwanhausser et al.'s protein abundance estimates are mostly 54 lower than established values for individual proteins in the literature and that statistical methods to quantitate the impact of experimental error had not been employed. We therefore set out to explore if we could refine the analysis of these datasets and to compare our results to those of Schwanhausser et al. and other system wide studies.

\section{RESULTS AND DISCUSSION}

\section{A non-linear underestimation of protein abundances}

Our starting point was a set of published abundances of 53 mammalian housekeeping proteins, most of which are based on SILAC mass spectrometry or western blot data (Biggin 2011; Brosi et al. 1993; Gregory et al. 2002; Hanamura et al. 1998; Kimura et al. 1999; Kislauskis et al. 1997; Princiotta et al. 2003; Wollfe 1998; Wong et al. 2011; Zeiler et al. 2012). On average these established estimates are 16 fold higher than those from Schwanhausser et al.'s original label free mass spectrometry data (Dataset S1). Once we brought this discrepancy to the authors' attention, they upwardly revised their abundance estimates for all 5,028 detected proteins and provided western blot or Selected Reaction Monitoring (SRM) mass spectrometry measurements for eight polypeptides in NIH3T3 cells (see Corrigendum (Schwanhausser et al. 2011)). However, Schwanhausser et al.'s second whole proteome abundance estimates are still lower than individual measurements for proteins expressed below $10^{6}$ molecules per cell, with the lowest abundance proteins showing the largest discrepancy (Fig. 2a; Dataset S1).

Western blot and SILAC mass spectrometry measurements show the same discrepancy versus the label free whole proteome data (Dataset S1). For example, for proteins expressed below 1 million molecules per cell, the 26 SILAC measurements are a median of 2.95 fold higher than Schwanhausser et al.'s second estimates, and the 19 western blot measurements are 3.10 fold higher. This suggests that the discrepancy is not due to error in the individual measurements as a similar bias in two independent methods is unlikely.

Of the 61 individual measurements of protein abundance available to us, 15 were made in $80 \mathrm{NIH} 3 \mathrm{~T} 3$ cells and 42 were made in HeLa cells. The discrepancy between Schwanhausser et 81 al.'s second whole proteome abundances and these individual measurements is not due to 82 differences in expression levels between HeLa and NIH3T3 cells for the following reasons. 
83 One, it is unlikely that such a difference would only occur for lower abundance proteins. Two,

84 five of the individual measurements for lower abundance proteins (Orc2, Orc4, HDAC3, NFkB1, 85 and NFkB2) were made in NIH3T3 cells and are on average 3.7 fold higher than the second 86 whole proteome estimates in this same cell line (Dataset S1). Three, later in the paper we show 87 that collectively the 61 individual proteins measured have on average the same relationship in 88 expression values versus all other cellular proteins in both NIH3T3 and HeLa cells. In addition, as further evidence we note that Schwanhausser et al.'s second estimates for RNA polymerase II and general transcription factors such as TFIIB and TFIIE are only 1.6 fold higher than those in yeast (Borggrefe et al. 2001) and are 7.1 times less than those in HeLa cells (Kimura et al. 1999). Yeast cells have $1 / 40^{\text {th }}$ the volume, $1 / 200^{\text {th }}$ the amount of DNA and $1 / 4$ the number of genes of NIH3T3 and HeLa cells (Milo et al. 2010). Two fold reductions in the concentrations of a single general transcription factor have, in some cases, phenotypic consequence (Aoyagi \& Wassarman 2001; Deutschbauer et al. 2005; Eissenberg et al. 2002; Kim et al. 2010). Thus, it is unlikely that a rapidly dividing mammalian cell could function with much larger reductions in the amounts of all of these essential regulators to levels close to those found in yeast.

\section{Correcting the non-linear bias}

Schwanhausser et al. calibrated protein abundances by spiking known amounts of protein standards into a crude protein extract from NIH3T3 cells and then measuring the abundances of several thousand proteins in the mixture by label free mass spectrometry. The 20 "spiked in" protein standards detected in this experiment, however, were present at the equivalent $>8.0 \mathrm{x}$ $10^{5}$ molecules per cell, a level that represents only the most highly expressed $11 \%$ of the proteins detected (Fig. 3a) (M. Selbach, personal communication (Schwanhausser et al. 2011)). To convert mass spectrometry signals to protein abundances, Schwanhausser et al. assumed that a linear relationship defined using the 20 "spiked in" standards holds true for proteins at all abundances (Fig. 3a). The discrepancy between the resulting estimates and individual protein measurements, however, suggests that this assumption is not valid. We therefore employed the 61 individual protein measurements from the literature as they span a much wider abundance range. In a plot of these data vs Schwanhausser et al.'s second whole proteome estimates, we found that a two-part linear regression gave a statistically better fit over a single regression (Fig. 3b and c) ( $p$-value $=0.002$, Materials and Methods). We then used this two-part regression to derive new abundance estimates for all 5,028 proteins in Schwanhausser et al.'s dataset (Dataset S1). As Figure 2b shows, the correction removes the non-linear bias. 
116 In our rescaled data, the median abundance protein is present at 170,000 molecules per cell

117 (Fig. 2b), considerably higher than Schwanhausser et al.'s original estimate of 16,000

118 molecules per cell and significantly above their second estimate of 50,000 molecules per cell.

119 For low abundance proteins the effect is larger. In our corrected data, the median sequence

120 specific transcription factor is present at 71,000 molecules per cell versus Schwanhausser et

121 al.'s estimates of first 3,500 then 9,300 molecules per cell (Dataset S1). Our correction reduces

+122 the range of detected abundances by $\sim 50$ fold (unlogged) compared to Schwanhausser et al.'s second estimates (Dataset S1) and the variance in protein levels from $0.97(\log 10)$ to 0.36 $(\log 10)$.

\section{Corrected protein abundances show an increased correlation with mRNA abundances}

As an independent check on the accuracy of our corrected abundances, we compared them to Schwanhausser et al.'s RNA-Seq mRNA expression data. Our corrected protein abundances correlate more highly with mRNA abundances than do Schwanhausser et al.'s second whole proteome estimates (compare Fig. $4 a$ and b). The increase in correlation coefficient is highly significant ( $p$-value $<10^{-29}$ ) (Materials and Methods), arguing that our non-linear correction to the whole proteome abundances has increased the accuracy of these estimates. The most dramatic change is that the scatter about the line of best fit is reduced and shows a stronger linear relationship. The $50 \%$ prediction band shows that prior to correction the half of proteins whose abundances are best predicted by mRNA levels are expressed over an 11 fold range (unlogged), but after correction they are expressed over a narrower, 4 fold range (Fig. $4 \mathrm{a}$ and b). The correction reduces the width of the $95 \%$ prediction band even further, by 18 fold.

137 For our corrected data, the median number of proteins translated per mRNA is 9,800 compared

138 to Schwanhausser et al.'s original estimate of 900 and their second estimate of 2,800. In yeast, 139 the ratio of protein molecules translated per mRNA is 4,200-5,600 (Ghaemmaghami et al. 140 2003; Lu et al. 2007). Given that mammalian cells have a higher protein copy number than 141 yeast (Milo et al. 2010), it is not unreasonable that the ratio in mammalian cells would be the 142 higher.

\section{Estimating the impact of molecule specific measurement error}

145 In addition to the above general error in scaling protein abundances, there are additional 146 sources of experimental error that uniquely affect data for each protein and mRNA differently. 147 As a result of these molecule specific measurement errors, the coefficient of determination 148 between measured mRNA and measured protein levels-i.e. $\mathrm{R}^{2}$ shown in Fig. 4b-is lower 
149 than the actual value between true protein and true mRNA levels. With an accurate estimate of

150 the errors, it is possible to calculate the increased correlation expected between true protein

151 and true mRNA abundances. Because the variance in the residuals in Fig. 4b (i.e. the

152 displacement along the $y$ axis of data points about the line of best fit) is composed of both

153 experimental error and the genuine differences in the rates of translation and protein

154 degradation between genes, once the experimental error has been estimated, it is also

possible to infer the combined true effects of translation and protein degradation.

There are two classes of molecule specific experimental error: stochastic and systematic.

Stochastic error, or imprecision, is the variation between replica experiments and is estimated from this variation. Systematic error, or inaccuracy, is the reproducible under or over estimation of each data point, and is estimated by comparing the results obtained with the assay being used to those from gold standard measurements obtained with the most accurate method available.

Schwanhausser et al. limited their estimation of experimental error to stochastic errors. Because our correction of the whole proteome abundances reduces the total variance in measured protein expression levels, we first reestimated the proportion of the variance in the residuals in Fig. $4 \mathrm{~b}$ that is due to stochastic measurement error using replica datasets (Materials and Methods). We find that $7 \%$ of this variance results from stochastic protein error and $0.8 \%$ from stochastic mRNA error.

168 Schwanhausser et al., however, also noted a significant variance between their whole genome 169 RNA-Seq data and NanoString measurements for 79 genes $\left(R^{2}=0.79\right.$ in Fig. S8A in 170 (Schwanhausser et al. 2011)), though they did not take this into account subsequently. RNA171 Seq is well known to suffer reproducible several fold biases in the number of DNA sequence 172 reads obtained for different GC content genomic regions (Cheung et al. 2011; Dohm et al. 173 2008). In contrast, NanoString gives an accurate measure of nucleic acid abundance as 174 correlation coefficients of $\mathrm{R}^{2}=0.99$ are obtained when NanoString data are compared to known 175 concentrations of nucleic acid standards (Geiss et al. 2008). Thus, it is reasonable to consider 176 NanoString as a gold standard that can be used to assess the systematic error in the RNA-seq 177 data by assuming that the variance between the two methods is due mostly to systematic error 178 in RNA-seq. Using Analysis of Variance (ANOVA), the variance in Schwanhausser et al.'s 179 NanoString/RNA-Seq comparison can be shown to be equivalent to $23.3 \%$ of the variation in 180 the residuals in Fig. 4b, 29 fold larger than the stochastic component of mRNA error (see 181 Materials and Methods for a discussion of the assumptions used in this analysis). 
182 It is also important to assess the systematic error in the whole proteome abundances as label 183 free mass spectrometry includes such biases (Bantscheff et al. 2012; Kuntumalla et al. 2009; 184 Lu et al. 2007; Peng et al. 2012). In principle the "spiked in" protein standards in 185 Schwanhausser et al.'s calibration experiment (i.e. the data in Fig. 3a) should provide gold 186 standard data. In practice, however, the variance in mass spectrometry estimates for protein 187 standards present at supposedly the same amounts is too high (i.e. the scatter along the $\mathrm{x}$ axis in Fig. 3a). This variance would contribute $61 \%$ to the variance in the residuals in Fig. $4 \mathrm{~b}$, yet the variance of the residuals between the corrected whole proteome estimates and the 61 individual protein measurements (i.e. the scatter along the $\mathrm{x}$ axis about the solid red line in Fig. $3 b)$ would contribute only $44 \%$. Since the western blot and SILAC methods used to make the 61 individual protein measurements introduce some experimental error, it seems likely that the commercial protein standards used by Schwanhauser at al. were not as accurately prepared at the correct protein concentrations as one would expect. Since no other suitable gold standard is available, we are thus unable to estimate the systematic protein error, though it is likely to be less $44 \%$ of variance in the residuals in Fig. $4 \mathrm{~b}$.

Taking the stochastic protein error as a minimum estimate of protein error and the variance from the NanoString/RNA-Seq comparison as an estimate of all RNA errors, it can be shown that true mRNA levels explain at least $56 \%$ of true protein levels, and by extension protein degradation and translation combined explain no more than $44 \%$ (see Materials and Methods).

201 Estimating the relative importance of transcription, mRNA degradation, translation and 202 protein degradation

203 In addition to determining protein and mRNA abundances, Schwanhausser et al. also directly 204 measured mRNA and protein degradation rates and calculated the percentage that each 205 contributed to the variance in protein abundances. Using this information, it is possible to 206 determine the relative importance of transcription, RNA degradation, translation and protein 207 degradation for different scenarios (Table 1, see Materials and Methods). For the 4,212 genes 208 whose protein and mRNA expression was detected, our analysis suggests that transcription 209 explains $\sim 38 \%$ of the variance in true protein levels, RNA degradation explains $\sim 18 \%$, 210 translation $\sim 30 \%$, and protein degradation $\sim 14 \%$ (Table 1). Clearly these estimates are 211 tentative and depend on the particular assumptions we have made. We believe, though, that 212 they will prove more accurate than Schwanhausser et al.'s suggestion that translation is the 213 predominant determinant of protein expression and that mRNA levels explain around $40 \%$ of 214 the variability in protein levels (Schwanhausser et al. 2011) (Table 1). 
216 Direct measurements of translation rates support our analysis

217 Direct measurements of system wide translation rates using ribosome profiling (Guo et al.

218 2010; Ingolia et al. 2011; Subtelny et al. 2013) provide independent evidence that translation 219 rates vary less than Schwanhausser et al. suggest. The distributions of the rates of translation 220 rates measured in mouse embryonic stem cells, mouse neutrophils, mouse NIH3T3 cells and human HeLa cells are all significantly narrower than Schwanhausser et al. inferred for mouse NIH3T3 cells (Fig. 5a; Table S1). For NIH3T3 cells the translation rates measured by ribosome profiling for $95 \%$ of the genes detected vary only 5.8 fold, but the rates inferred for $95 \%$ of genes by Schwanhausser et al. vary 115 fold (Fig. 5a). Because each of these datasets contain differing numbers of genes (Table S1), to provide a more direct comparison we took the intersection of genes detected by Schwanhausser et al. and by ribosome profiling in NIH3T3 cells (Fig. 5b). The variance in measured translation rates for the genes in the intersection is only $12 \%$ of the variance in rates inferred by Schwanhausser et al. for these same genes (Fig. $5 b$; Table S1).

Having direct measurements of the variance in translation rates opens up a second strategy to estimate the relative importance of each step in gene expression (Materials and Methods). In our first strategy - the measured protein error strategy-protein degradation rates and errors in protein and mRNA abundances were determined from direct experimental data; and the variance in true protein levels explained by translation was inferred as that part of the variance in the residuals in Fig. $4 \mathrm{~b}$ that is not explained by the three experimentally measured terms. In our second strategy - the measured translation strategy - translation rates, protein degradation rates and mRNA errors are determined from direct experimental data; and the variance in measured protein levels explained by protein error is inferred as that part of the variance in the residuals in Fig. 4a that is not explained by the sum of variances of the three experimentally measured components (Materials and Methods). This measured translation strategy is thus independent of our rescaling of Schwanhausser et al.'s second protein abundance estimates and of our estimate of stochastic protein measurement error.

243 According to our second strategy, for NIH3T3 cells the variance in true protein levels is $63 \%$ of 244 the variance in Schwanhausser et al.'s measured protein abundances; mRNA levels contribute $24581 \%$ to the variance in true protein expression; transcription $71 \%$; RNA degradation $10 \%$; 246 translation 11\%; and protein degradation 8\% (Table 1). Despite the significant differences in 247 the underlying data and assumption used, these results agree broadly with those of our first 
248 strategy (Table 1). Both strategies suggest that the variance in Schwanhausser et al.'s second 249 protein abundance estimates is too high. Both suggest that translation contributes less to 250 protein levels and that transcription contributes more that Schwanhausser et al. claimed. In 251 effect, the measured rates of translation provide independent support for our rescaling of 252 Schwanhausser et al.'s protein abundances and our estimates of stochastic protein error, and 253 visa versa.

Our second strategy, though, does estimate that mRNA levels and transcription explain a higher percent of protein expression than the first (Table 1), but this is not entirely unexpected. In our first strategy, we were not able to take account of systematic, molecule specific errors in protein abundances because appropriate control measurements were not available. Thus, this first strategy could well have underestimated error. In contrast, our second strategy estimates all types of protein abundance errors in a single term and thus has the potential to be the more accurate if the error in the ribosome profiling and protein degradation data is not too large.

To further explore the relationship between our two strategies, we compared the correlation between translation rates inferred by Schwanhausser et al. and those measured by ribosome profiling in NIH3T3 cells (Fig. 6). The coefficient of determination is small $\left(R^{2}=0.13\right)$, indicating that the ribosome profiling data explain only $13 \%$ of the variance in Schwanhausser et al.'s inferred rates. Considered in isolation this result does not establish if the poor correlation is due to errors in either or both datasets. However, our measured protein error strategy shows that the variance in true translation rates contributes no more than $19 \%$ to the variance in Schwanhausser et al.'s inferred translation rates, with the remaining $81 \%$ of the variance being due to experimental error $($ Table $1 ; 0.19=(0.34 \times 0.30) /(0.97 \times 0.55))$. The close agreement of this estimate with the actual correlation between measured and inferred translation rates $\left(R^{2}<=0.19\right.$ vs $\left.R^{2}=0.13\right)$ suggests that the poor correlation is almost entirely due to error in Schwanhausser et al.'s inferred rates. In addition, this result provides further evidence that our two strategies broadly agree, with the measured protein error strategy potentially

274 underestimating the degree of error in Schwanhausser et al.'s data.

Ribosome profiling has also shown that translation rates change only several fold upon cellular differentiation and, with the exception of the translation machinery, the change affects all expressed genes to a similar degree (Ingolia et al. 2011). Other system wide studies, including a separate analysis by Schwanhausser et al., also suggest that the differential regulation of translation may be limited to modest changes at a subset of genes (Baek et al. 2008; Hsieh et al. 2012; Kristensen et al. 2013; Schwanhausser et al. 2011; Selbach et al. 2008). This work 
seems consistent with our analysis and suggests that translation may be used chiefly to fine

282 tune protein expression levels.

\section{Estimating the number of non-transcribed genes}

284 Both Schwanhausser et al.'s and all of our analyses presented above consider only those 285 genes whose protein and mRNA expression was detected. There are many thousands of other genes, however, which express no mRNA and as a result cannot be translated. To estimate the proportion of such genes in a typical cell, we made use of a detailed analysis by Hebenstreit et al, who showed that there is a trimodal distribution of mRNA expression when the data is derived as an average for a population of cells of a single cell type (Hebenstreit et al. 2012; Hebenstreit et al. 2011) (Fig. S1). The first mode contains Highly Expressed (HE) genes, present at one or more molecules per cell; the second mode is comprised of Low Expressed (LE) genes, which are not expressed in most cells but-as shown by single molecule fluorescent in situ hybridization-are present at one to several molecules per cell in a small percent of cells; and the third mode contains genes that are not detectably expressed (NE genes) and thus, given the assays sensitivity, are present at less than one mRNA molecule per 100 cells. LE genes tend to be closer to HE genes on the chromosome than are NE genes, and it has been suggested that this proximity may allow escape from repressive chromatin structures in a few cells, explaining the stochastic bursts of rare transcription observed (Hebenstreit et al. 2012; Hebenstreit et al. 2011).

To account for variation in the expression of individual genes between cells, which all LE genes at a minimum must suffer, we assume that the general distribution of mRNA expression levels does not vary from cell to cell even when the expression of individual genes does. The mRNA expression of each LE gene was divided into a component representing expression of one mRNA molecule in some cells and a second component representing the remaining cells that express no mRNA (Materials and Methods). This yields 8,763 NE and LE gene equivalents that are not expressed and 12,546 LE and HE gene equivalents that are expressed. For the 8,763 non-expressed gene equivalents, the complete absence of their mRNAs from the cell means that they are not being translated in these cells. Therefore, there can be no variation in the rates at which they are translated. Instead, we assume that the absence of transcription is overwhelmingly the reason why these genes express no protein. 


\section{Implication for other system wide studies}

313 Two other system wide estimates of protein abundance in mammalian cells are, like

314 Schwanhausser et al.'s, lower than ours. These two reports suggest that the median

315 abundance protein detected is present at 8,000 (Vogel et al. 2010) or 9,700 (Beck et al. 2011)

316 molecules per cell vs our estimate of 170,000 molecules per cell. Since these lower estimates

317 provide less than $1 / 10^{\text {th }}$ of the number of histones needed to cover the diploid genome with

+318 nucleosomes and are lower than published estimates for a wide array of other housekeeping

19 proteins, it is unlikely that they are accurate.

Another study by Wisniewski et al. provided protein abundance estimates for HeLa cells that are generally higher than ours and spread over a broader range (Wisniewski et al. 2012) (Fig. 7a). These estimates are $240 \%$ higher on average than the set of individual protein measurements from the literature (Dataset S3, Fig. 7b). Since over $80 \%$ of these individual measurements were made for proteins in HeLa cells, Wisniewski et al.'s estimates must be incorrectly scaled. Using our two part linear regression strategy, we therefore corrected Wisniewski et al.'s whole proteome data (Materials and Methods, Fig. S2; Dataset S3), bringing the average variation between the whole proteome estimates and individual protein measurements to within $6 \%$ of each other (Fig. 7b; Dataset S3). Interestingly, the correction dramatically increases the similarity between the distributions of protein abundances in HeLa and NIH3T3 cells for all orthologous proteins (Fig. 7a). This establishes the important point, mentioned at the beginning of the Results, that in aggregate the $60+$ housekeeping proteins show a similar relationship to the expression values of all other cellular proteins in both cell lines, and thus the discrepancies with the uncorrected whole proteome data are not due to differences in expression levels in HeLa versus NIH3T3 cells. The correction also increases the correlation between HeLa cell protein and HeLa mRNA abundances to a statistically significant extent ( $p$-value, $6 \times 10^{-20}$ ) and reduces the $50 \%$ and $95 \%$ confidence bounds for this relationship by 1.7 fold and 4.6 fold respectively. Wisniewski et al. scaled their protein abundances using the total cellular protein content and the sum of the mass spectrometry signals for all detected polypeptides. They assumed that mass spectrometry signals are proportional to protein abundance. In contrast, our scaling strategy makes no such assumption and instead uses many individual measurements of housekeeping proteins to estimate a multipart (spline) function. The increased correlations obtained with individual protein measurements and with mRNA abundances for two cell lines suggests that our scalings are the more accurate. 
345 Other estimates for the contribution of mRNA levels in determining protein expression in 346 mammals are lower than ours, suggesting that mRNA levels contribute 10\%-40\% (Maier et al. 347 2009; Vogel \& Marcotte 2012). In comparison, we estimate that mRNA abundance explains $34856 \%-81 \%$ for a set of 4,212 detected proteins. We also have suggested that for the $40 \%$ of 349 genes in a given cell that express no mRNA, translation rates likely play no role in determining 350 protein expression levels. The other groups' neither took systematic experimental errors into account or made use of direct measures of translation rates and generally do not discuss nontranscribed genes. For this reason, we suspect their analyses underestimate the contribution of transcription.

\section{CONCLUSIONS}

Quantitative whole proteome analyses can offer profound insights into the control of gene expression and provide baseline parameters for much of systems biology. As these important new technologies continue to be refined, it is critical that the data be correctly scaled, that experimental errors be measured and accounted for as much as possible, that all genes be considered, and that direct measurements of each step in gene expression be made. Additional measurements and controls will be needed to derive a more assured system wide understanding of protein and mRNA abundances and the relative importance of each of the four steps in gene expression.

\section{MATERIALS AND METHODS}

\section{Correcting protein abundance}

367 For NIH3T3 cells, all credible individual protein abundance measurements available to us for 368 housekeeping proteins (a total of 61 proteins, Dataset S1) were $\log _{10}$ transformed along with 369 the corresponding estimates from Schwanhausser et al.'s second whole proteome dataset. 370 Model selection of different regressive models by leave-one-out cross-validation was used to fit 371 the training data (Bickel \& Doksum 2001). This showed that a plausible two-part linear 372 regression with a change point at $10^{6}$ molecules per cell (line $<1 \times 10^{6} \ldots$ slope $=0.56$, 373 intercept $=2.64$; line $>1 \times 10^{6} \ldots$ slope $=1.06$, intercept=-0.41) fit the data far better than by chance 374 (likelihood ratio test bootstrap p-value=0.002 (Bickel \& Doksum 2001); Fig. 3b and c). The 375 resulting two-part linear model was used to correct all 5,028 protein abundance estimates (Fig. 376 2b, Dataset S1). 
377 The null hypothesis that the correlation coefficient of the uncorrected Schwanhausser et al.

378 protein abundance estimates vs mRNA estimates $\left(R_{1}=0.626\right)$ is equal to that of our corrected 379 protein estimates vs mRNA estimates $\left(R_{2}=0.642\right)$ was tested. The method for comparing 380 dependent correlation coefficients (Olkin \& Finn 1990) was employed because both 381 correlations involve the same mRNA-seq data and it is reasonable to assume that the 382 uncorrected and corrected protein abundance estimates and the mRNA estimates have a multivariate Gaussian distribution. The resulting two-sided $p$-value $<10^{-29}$ shows that $R_{2}$ is significantly larger than $\mathrm{R}_{1}$.

To correct protein abundance estimates for HeLa cells (Wisniewski et al. 2012), the same strategy used for NIH3T3 cells was used. A two-part linear regression with a change point at $10^{6.8}$ molecules per cell fit the data far better than by accident (likelihood ratio test bootstrap pvalue $=0.001$ ) (Fig. S2). The resulting two-part linear model was used to correct all HeLa cell protein abundance estimates (Fig. 7; Dataset S3). The correlation of HeLa cell protein abundance estimates with mRNA abundances was determined using the mean values of replica HeLa cell RNA-Seq datasets from the ENCODE consortium (Consortium 2011) (GEO Accession ID "GSM765402"). The hypothesis that our corrected protein abundances correlate more highly with these HeLa mRNA abundances than the uncorrected estimates was tested as above, resulting in a two sided $p$-value of $6 \times 10^{-20}$.

\section{The contribution of mRNA to protein levels: measured protein error strategy}

The variance term in a linear model between measured protein abundance (MP) (response) and measured mRNA levels (MR) (predictor) is decomposed in a standard way (ANOVA (Bickel \& Doksum 2001)) into three components (Fig. 8). These components of the variance in the residuals represent mRNA measurement error $\left(e_{R}\right)$, protein measurement error $\left(e_{P}\right)$, and 400 the variance in a linear model between true protein abundance (TP) and true mRNA levels (TR) 401 that results from the centered genuine differences in the rates of protein degradation and 402 translation (PDT). The measured protein abundances considered in this case are our rescaled 403 estimates.

$404 \quad$ Statistically, we can write three linear models from Figure 8.

$$
T R=b_{R} M R+c_{R}+e_{R}
$$


where TR, MR, TP, MP are abundance values on a $\log _{10}$ scale; the three sources of variation ( $e_{R}, e_{P}$ and PDT) are assumed to be independent random variables with mean 0 ; the amount of protein degradation and translation (PDT) is taken to be independent of true mRNA levels (TR) on the basis of partial evidence: the variance in the residuals in Figure $4 \mathrm{~b}$ is similar for different mRNA abundances; the reversal of the causal relationship between TR and MR in model (1) assumes that TR and MR have an approximately joint Gaussian distribution; the slope of TP in model (3) is assumed to be 1 because the ratios between the 61 protein published abundance measurements and our corrected estimates are close to 1 (Fig. 2b); and finally we note that implicit in the analysis of variance is the assumption that the various datasets employed can thought of as originating from a relatively homogeneous superpopulation. Combining (1)-(3), we write the linear model between measured protein abundance and measured mRNA levels as

$$
M P=b b_{R} M R+b c_{R}+c+c_{P}+b e_{R}+P D T+e_{P}
$$

\section{Based on model (4)}

i. We first estimated $\operatorname{var}\left(b e_{R}+P D T+e_{P}\right)$ as $\sigma_{\text {all }}^{2}$ and $b b_{R}$ as $\hat{b}_{\text {all }}$ from fitting the above model with the 8,424 corrected mass spec and RNA-Seq data points pooled from the two replicates (Dataset S1). By independence, we have

$$
\operatorname{var}\left(b e_{R}+P D T+e_{P}\right)=b^{2} \operatorname{var}\left(e_{R}\right)+\operatorname{var}(P D T)+\operatorname{var}\left(e_{P}\right)
$$

ii. We next estimated $\operatorname{var}\left(e_{R}\right)$ as $\hat{\sigma}_{R}^{2}$ and $b_{R}$ as $\hat{b}_{R}$ from fitting model (1) with the 77 NanoString (“TR”) vs RNA-Seq (“MR”) data points, after removing two outliers (Dataset S2).

iii. We could not estimate $\operatorname{var}\left(e_{P}\right)$ from directly fitting model (3), as TP data is not available. As a surrogate, we estimated $\operatorname{var}\left(e_{P}\right)$ as $\hat{\sigma}_{P}^{2}$ from the following linear model that quantifies the stochastic error in mass spec replicate data:

$$
M P_{i j}=\operatorname{avgMP}+\left(e_{P}\right)_{i j}, \mathrm{j}=1,2
$$

where $M P_{i j}$ is the corrected mass spec data for the ith protein in the jth replicate in Schwanhausser et al., and $\operatorname{avgMP}_{i}$ is the average of our corrected protein data for the ith protein, $i=1, \ldots, 4,212$ (Dataset S1). Please note that $\hat{\sigma}_{P}^{2}$ is potentially an underestimate of the protein error as we only consider the stochastic error, not the systematic error.

iv. From the estimates $\sigma_{\text {all }}^{2}, \hat{b}_{\text {all }}, \hat{\sigma}_{R}^{2}, \hat{b}_{R}$ and $\hat{\sigma}_{P}^{2}$ above, we estimate var(PDT) as 


$$
\hat{\sigma}_{P D T}^{2}=\hat{\sigma}_{\text {all }}^{2}-\left(\frac{\hat{b}_{\text {all }}}{\hat{b}_{R}}\right)^{2} \hat{\sigma}_{R}^{2}-\hat{\sigma}_{P}^{2}
$$

437 Hence, we have successfully decomposed the variance estimate $\hat{\sigma}_{\text {all }}^{2}$, i.e. the estimated 438 variance of residuals between measured protein levels and measured mRNA levels, into 3 439 components:

- $\hat{\sigma}_{R}^{2}-$ RNA error $\left(23.3 \%\right.$ of $\left.\sigma_{\text {all }}^{2}\right)$

- $\hat{\sigma}_{P}^{2}-$ protein error $\left(7 \%\right.$ of $\left.\sigma_{\text {all }}^{2}\right)$

- $\quad \hat{\sigma}_{P D T}^{2}$ - protein degradation \& translation $\left(69.6 \%\right.$ of $\left.\sigma_{\text {all }}^{2}\right)$

From the diagram and the above calculation, we also derived the percentage of variability in the unobserved true protein levels explained by the unobserved true mRNA levels.

$$
\frac{\hat{\sigma}_{M P}^{2}-\hat{\sigma}_{P}^{2}-\hat{\sigma}_{P D T}^{2}}{\hat{\sigma}_{M P}^{2}-\hat{\sigma}_{P}^{2}}=55.9 \%
$$

where $\hat{\sigma}_{M P}^{2}$ is the variance of the corrected measured protein levels.

We separately estimated the stochastic mRNA error from the replicate RNA-Seq measurements of the 4,212 genes (Dataset S1). The stochastic mRNA error contributes $0.8 \%$ of $\sigma_{\text {all }}^{2}$.

450

The contributions of transcription, translation and protein and mRNA degradation: measured error strategy

To determine the relative contributions of measured RNA degradation (RD) and measured protein degradation (PD) to the variance in true protein expression (TP), we estimated their variances, $\operatorname{var}(\mathrm{RD})$ and $\operatorname{var}(\mathrm{PD})$. We took Schwanhausser et al.'s calculated percentages for the contribution of $\mathrm{RD}$ and $\mathrm{PD}$ to explain the variance of their uncorrected mass whole proteome abundances (Schwanhausser et al. 2011) (6.4\% for RD and 4.9\% PD, Matthias Selbach personal communication). Since the variance of the 8,424 uncorrected mass spec data points from the two replicates is 0.97 , we thus calculated $\operatorname{var}(R D)$ and $\operatorname{var}(P D)$ as 0.062 and 0.048 respectively. The relative contributions of $\operatorname{var}(\mathrm{RD})$ and $\operatorname{var}(\mathrm{PD})$ to $\operatorname{var}(\mathrm{TP})$ (estimated as $\hat{\sigma}_{M P}^{2}-\hat{\sigma}_{P}^{2}$ ) was calculated (Table 1). We also determined the contribution of transcription $(\operatorname{var}(T X N))$ to $\operatorname{var}(T P)$ as $(\operatorname{var}(T R)-\operatorname{var}(\operatorname{true} R D)) / \operatorname{var}(T P)$, where $\operatorname{var}(T R)$ was estimated as 
$463 \hat{\sigma}_{M P}^{2}-\hat{\sigma}_{P}^{2}-\hat{\sigma}_{P D T}^{2}$, and the contribution of translation as (var(TP)-var(TR)-var(true PD))/var(TP)

464 (Table 1).

465 The contributions of each step of gene expression to protein levels: measured 466 translation strategy

467 We calculated the relative contributions of each of the four steps in gene expression by an +468 independent, second approach that does not rely either on our rescaling of Schwanhausser et al.'s protein abundance estimates or on our estimate of stochastic protein errors. Instead, our second approach infers true protein abundance based on Subtelny et al.'s direct measurements of translation rates in NIH3T3 cells by ribosome profiling (Subtelny et al. 2013) and on our estimate of RNA measurement error. The measured protein abundances considered are thus Schwanhausser et al.'s second estimates, not our rescaling of these estimates. A central assumption is that since the variance in Subtelny et al.'s measured translation rates is $12 \%$ of the variance in the rates of translation inferred by Schwanhausser et al., then the contribution of translation to the variance in true protein levels is $12 \%$ of the value provided by Schwanhausser et al.

The variance term in a linear model between measured protein abundance (MP) and measured mRNA levels (MR) was decomposed as before (Fig. 8) except that the variance in the linear model between true protein abundance (TP) and true mRNA levels (TR) that results from the variance in the rates of protein degradation (PD) and protein translation (PT) were considered 482 separately as CPD and dPT respectively. Similar to our measured error strategy, we can write 483 three linear models using the same assumptions.

$$
T R=b_{R} M R+c_{R}+e_{R}
$$

$$
T P=b T R+c P D+d P T+f
$$

$$
M P=T P+c_{P}+e_{P}
$$

487 Thus, we can write the linear model between measured protein abundance (MP) and measured 488 mRNA levels (MR) for the measured translation strategy as

$$
M P=b b_{R} M R+b c_{R}+f+c_{P}+b e_{R}+c P D+d P T+e_{p}
$$


491 i. We first estimated $\operatorname{var}\left(b e_{R}+c P D+c P T+e_{P}\right)$ as $\hat{\sigma}_{\text {all }}^{2}$ and $b b_{R}$ as $\hat{b}_{\text {all }}$ from fitting the above 492 model with the 8,424 mass spec and RNA-Seq data points pooled from the two replicates 493 using Schwanhausser's second estimates (Dataset S1). By independence, we thus have

ii. The values of $\operatorname{var}\left(e_{R}\right)$ and $b_{R}$ are the same as those derived previously by our measured error strategy. Thus, we can estimate $\hat{b}=\hat{b}_{\text {all }} / \hat{b}_{R}$

iii. We used the estimate of $\operatorname{var}(c P D)$ from Schwanhausser et al., i.e., $0.97 \times 5 \%=0.0475$.

iv. From Schwanhausser et al.'s results, we have $\operatorname{var}(d P T)=d^{2} \operatorname{var}(P T)$ estimated as $0.97 \times$ $55 \%=0.54$. From Schwanhausser et al.'s estimates for each of 3,633 genes (Dataset S1, second tab, column AG) $\operatorname{var}(P T)$ has an estimate of 0.29 . Hence, the estimate of $d^{2}$ is 1.86. From Subtelny et al., we have a separate, directly measured estimate of $\operatorname{var}(P T)$ as 0.03533, which we obtained by slightly increasing the variance of their data for the 3,126 genes in the intersected dataset (Fig. 5B; Table S1) by the ratio of the variances for Schwanhusser et al.'s inferred rates for the 3,633 genes and the 3,126 genes (Table S1). Using this value to replace that of Schwanhausser et al., we obtained a new estimate of 505 506 $\operatorname{var}(d P T)=d^{2} \operatorname{var}(P T)$ as $1.86 \times 0.03533=0.06593132$.

v. Now we can estimate $\operatorname{var}\left(e_{P}\right)$ as $\hat{\sigma}_{P}^{2}=\hat{\sigma}_{\text {all }}^{2}-\hat{b} \hat{\sigma}_{R}^{2}-\hat{\sigma}_{c P D}^{2}-\hat{\sigma}_{d P T}^{2}$ were $\hat{\sigma}_{c P D}^{2}$ is an estimate of 508 $\operatorname{var}(\mathrm{cPD})$ and $\hat{\sigma}_{d P T}^{2}$ an estimate of $\operatorname{var}(\mathrm{dPT})$.

vi. Given Schwanhausser et al.'s second 8,424 uncorrected mass spec data, we can also estimate $\operatorname{var}(\mathrm{TP})$ as $\hat{\sigma}_{T P}^{2}=\hat{\sigma}_{M P}^{2}-\hat{\sigma}_{P}^{2}$, where $\hat{\sigma}_{M P}^{2}$ is an estimate of $\operatorname{var}(\mathrm{MP})$.

511 Given the estimates $\hat{\sigma}_{c P D}^{2}$ and $\hat{\sigma}_{d P T}^{2}$ and Schwanhausser et al.'s estimate of the contribution of 512 the variance in RNA degradation (defined as $\hat{\sigma}_{g R D}^{2}$ ), we can decompose $\hat{\sigma}_{T P}^{2}$ as:

513 - variance explained by PD: $\hat{\sigma}_{c P D}^{2} / \hat{\sigma}_{T P}^{2}$

514 - variance explained by PT: $\hat{\sigma}_{d P T}^{2} / \hat{\sigma}_{T P}^{2}$

515 - variance explained by TR: $1-\frac{\hat{\sigma}_{c P D}^{2}}{\hat{\sigma}_{T P}^{2}}-\frac{\hat{\sigma}_{d P T}^{2}}{\hat{\sigma}_{T P}^{2}}$ 
- variance explained by RD: $\hat{\sigma}_{g R D}^{2} / \hat{\sigma}_{T P}^{2}$

517 - variance explained by TXN: $1-\frac{\hat{\sigma}_{c P D}^{2}}{\hat{\sigma}_{T P}^{2}}-\frac{\hat{\sigma}_{d P T}^{2}}{\hat{\sigma}_{T P}^{2}}-\frac{\hat{\sigma}_{g R D}^{2}}{\hat{\sigma}_{T P}^{2}}$

\section{The number of genes not transcribed in a typical cell within a population.}

519 To estimate the number of genes not transcribed in a typical cell within a population, we 520 employed a deep RNA-Seq dataset that detected polyA+ mRNA for 15,325 protein coding genes in mouse Th2 cells (Hebenstreit et al. 2011). To place these abundance estimates on the same scale as those of Schwanhausser et al.'s data the 3,841 mRNAs expressed above 1 RPKM (reads per kilobase of exon per million mapped reads) in common between the two datasets were identified. The Th2 cell data were then scaled to have the same median and variance for these common genes in numbers of mRNA molecules per cell (Fig. S3). Following Hebenstreit et al., we divided the expressed genes into 11,301 Highly Expressed (HE) genes, present at one or more mRNA molecule per cell, and 4,024 Low Expressed (LE) genes, expressed below one molecule per cell. The remaining 5,984 genes whose expression was not detected were designated Not Expressed (NE) genes. We then divided each LE gene into two: a fraction of a gene expressed at 1 molecule per cell with a weight $w$ and a fraction of a gene that is not expressed in any cells with a weight 1-w. The 4,024 LE genes were thus decomposed into 1,245 gene equivalents expressed at 1 molecules per cell and 2,779 gene equivalents that are not expressed. Combining these with the 11,301 HE genes and 5,984 NE genes, we obtained 12,546 HE and LE expressed gene equivalents and 8,763 NE and LE nonexpressed gene equivalents.

\section{ACKNOWLEDGEMENTS}

538 We are indebted to Matthias Selbach for providing his second whole proteome abundance 539 estimates and ancillary data from the Schwanhausser et al. analysis. We acknowledge his 540 patient answering of our questions about the Schwanhausser et al. paper. We are particularly 541 grateful to Stephen Eichhorn and David Bartel for generously providing their ribsome profiling 542 data for NIH3T3 cells prior to publication. We also thank Sarah Teichmann for helping us better 543 understand the Hebenstreit et al. analysis of mRNA expression and Susan Celniker, Ben

544 Brown, and David Knowles for constructive comments on our manuscript. 


\section{REFERENCES}

546 Ambros V. 2011. MicroRNAs and developmental timing. Curr Opin Genet Dev 21:511-517.

547 Aoyagi N, and Wassarman DA. 2001. Developmental and transcriptional consequences of mutations in Drosophila TAF(II)60. Mol Cell Biol 21:6808-6819.

Baek D, Villen J, Shin C, Camargo FD, Gygi SP, and Bartel DP. 2008. The impact of microRNAs on protein output. Nature 455:64-71.

Bantscheff M, Lemeer S, Savitski MM, and Kuster B. 2012. Quantitative mass spectrometry in proteomics: critical review update from 2007 to the present. Anal Bioanal Chem 404:939-965.

Beck M, Schmidt A, Malmstroem J, Claassen M, Ori A, Szymborska A, Herzog F, Rinner O, Ellenberg J, and Aebersold R. 2011. The quantitative proteome of a human cell line. Mol Syst Biol 7:549.

Bickel PJ, and Doksum KA. 2001. Mathematical Statistics: Basic Ideas and Selected Topics. Upper Saddle River: Prentice Hall.

Biggin MD. 2011. Animal transcription networks as highly connected, quantitative continua. Dev Cell 21:611-626.

Boisvert FM, Ahmad Y, Gierlinski M, Charriere F, Lamont D, Scott M, Barton G, and Lamond Al. 2012. A quantitative spatial proteomics analysis of proteome turnover in human cells. Mol Cell Proteomics 11:M111 011429.

Borggrefe T, Davis R, Bareket-Samish A, and Kornberg RD. 2001. Quantitation of the RNA polymerase II transcription machinery in yeast. J Biol Chem 276:47150-47153.

Brosi R, Hauri HP, and Kramer A. 1993. Separation of splicing factor SF3 into two components and purification of SF3a activity. J Biol Chem 268:17640-17646.

Cambridge SB, Gnad F, Nguyen C, Bermejo JL, Kruger M, and Mann M. 2011. Systems-wide proteomic analysis in mammalian cells reveals conserved, functional protein turnover. $J$ Proteome Res 10:5275-5284.

Cheadle C, Fan J, Cho-Chung YS, Werner T, Ray J, Do L, Gorospe M, and Becker KG. 2005. Control of gene expression during $T$ cell activation: alternate regulation of $\mathrm{mRNA}$ transcription and mRNA stability. BMC Genomics 6:75.

Cheung MS, Down TA, Latorre I, and Ahringer J. 2011. Systematic bias in high-throughput sequencing data and its correction by BEADS. Nucleic Acids Res 39:e103.

Consortium TEP. 2011. A user's guide to the encyclopedia of DNA elements (ENCODE). PLoS Biology 9:e1001046. 
de Sousa Abreu R, Penalva LO, Marcotte EM, and Vogel C. 2009. Global signatures of protein and mRNA expression levels. Mol Biosyst 5:1512-1526.

Deutschbauer AM, Jaramillo DF, Proctor M, Kumm J, Hillenmeyer ME, Davis RW, Nislow C, and Giaever G. 2005. Mechanisms of haploinsufficiency revealed by genome-wide profiling in yeast. Genetics 169:1915-1925.

Dohm JC, Lottaz C, Borodina T, and Himmelbauer H. 2008. Substantial biases in ultra-short read data sets from high-throughput DNA sequencing. Nucleic Acids Res 36:e105.

Eden E, Geva-Zatorsky N, Issaeva I, Cohen A, Dekel E, Danon T, Cohen L, Mayo A, and Alon U. 2011. Proteome half-life dynamics in living human cells. Science 331:764-768.

Eissenberg JC, Ma J, Gerber MA, Christensen A, Kennison JA, and Shilatifard A. 2002. dELL is an essential RNA polymerase II elongation factor with a general role in development. Proc Natl Acad Sci U S A 99:9894-9899.

Elmen J, Lindow M, Schutz S, Lawrence M, Petri A, Obad S, Lindholm M, Hedtjarn M, Hansen HF, Berger U, Gullans S, Kearney P, Sarnow P, Straarup EM, and Kauppinen S. 2008. LNA-mediated microRNA silencing in non-human primates. Nature 452:896-899. Geiss GK, Bumgarner RE, Birditt B, Dahl T, Dowidar N, Dunaway DL, Fell HP, Ferree S, George RD, Grogan T, James JJ, Maysuria M, Mitton JD, Oliveri P, Osborn JL, Peng T, Ratcliffe AL, Webster PJ, Davidson EH, Hood L, and Dimitrov K. 2008. Direct multiplexed measurement of gene expression with color-coded probe pairs. Nat Biotechnol 26:317-325.

Gennarino VA, D'Angelo G, Dharmalingam G, Fernandez S, Russolillo G, Sanges R, Mutarelli M, Belcastro V, Ballabio A, Verde P, Sardiello M, and Banfi S. 2012. Identification of microRNA-regulated gene networks by expression analysis of target genes. Genome Res 22:1163-1172.

Ghaemmaghami S, Huh WK, Bower K, Howson RW, Belle A, Dephoure N, O'Shea EK, and Weissman JS. 2003. Global analysis of protein expression in yeast. Nature 425:737741.

Gregory SG, Sekhon M, Schein J, Zhao S, Osoegawa K, Scott CE, Evans RS, Burridge PW, Cox TV, Fox CA, Hutton RD, Mullenger IR, Phillips KJ, Smith J, Stalker J, Threadgold GJ, Birney E, Wylie K, Chinwalla A, Wallis J, Hillier L, Carter J, Gaige T, Jaeger S, Kremitzki C, Layman D, Maas J, McGrane R, Mead K, Walker R, Jones S, Smith M, Asano J, Bosdet I, Chan S, Chittaranjan S, Chiu R, Fjell C, Fuhrmann D, Girn N, Gray C, Guin R, Hsiao L, Krzywinski M, Kutsche R, Lee SS, Mathewson C, McLeavy C, Messervier S, Ness S, Pandoh P, Prabhu AL, Saeedi P, Smailus D, Spence L, Stott J, Taylor S, Terpstra W, Tsai M, Vardy J, Wye N, Yang G, Shatsman S, Ayodeji B, Geer 
613

614

615

616

617

618

$+519$

$-520$

(821

$\sqrt{5} 22$

K, Tsegaye G, Shvartsbeyn A, Gebregeorgis E, Krol M, Russell D, Overton L, Malek JA, Holmes M, Heaney M, Shetty J, Feldblyum T, Nierman WC, Catanese JJ, Hubbard T, Waterston RH, Rogers J, de Jong PJ, Fraser CM, Marra M, McPherson JD, and Bentley DR. 2002. A physical map of the mouse genome. Nature 418:743-750.

Guo H, Ingolia NT, Weissman JS, and Bartel DP. 2010. Mammalian microRNAs predominantly act to decrease target mRNA levels. Nature 466:835-840.

Han K, Jaimovich A, Dey G, Ruggero D, Meyuhas O, Sonenberg N, and Meyer T. 2013. Parallel measurement of dynamic changes in translation rates in single cells. Nat Methods.

Hanamura A, Caceres JF, Mayeda A, Franza BR, Jr., and Krainer AR. 1998. Regulated tissuespecific expression of antagonistic pre-mRNA splicing factors. RNA 4:430-444.

Hebenstreit D, Deonarine A, Babu MM, and Teichmann SA. 2012. Duel of the fates: the role of transcriptional circuits and noise in CD4+ cells. Curr Opin Cell Biol 24:350-358.

Hebenstreit D, Fang M, Gu M, Charoensawan V, van Oudenaarden A, and Teichmann SA. 2011. RNA sequencing reveals two major classes of gene expression levels in metazoan cells. Mol Syst Biol 7:497.

Hentze MW, and Kuhn LC. 1996. Molecular control of vertebrate iron metabolism: mRNAbased regulatory circuits operated by iron, nitric oxide, and oxidative stress. Proc NatI Acad Sci U S A 93:8175-8182.

Hobert O. 2008. Gene regulation by transcription factors and microRNAs. Science 319:17851786.

Hsieh AC, Liu Y, Edlind MP, Ingolia NT, Janes MR, Sher A, Shi EY, Stumpf CR, Christensen C, Bonham MJ, Wang S, Ren P, Martin M, Jessen K, Feldman ME, Weissman JS, Shokat KM, Rommel C, and Ruggero D. 2012. The translational landscape of mTOR signalling steers cancer initiation and metastasis. Nature 485:55-61.

Ingolia NT, Lareau LF, and Weissman JS. 2011. Ribosome profiling of mouse embryonic stem cells reveals the complexity and dynamics of mammalian proteomes. Cell 147:789-802.

Kim DU, Hayles J, Kim D, Wood V, Park HO, Won M, Yoo HS, Duhig T, Nam M, Palmer G, Han S, Jeffery L, Baek ST, Lee H, Shim YS, Lee M, Kim L, Heo KS, Noh EJ, Lee AR, Jang YJ, Chung KS, Choi SJ, Park JY, Park Y, Kim HM, Park SK, Park HJ, Kang EJ, Kim HB, Kang HS, Park HM, Kim K, Song K, Song KB, Nurse P, and Hoe KL. 2010. Analysis of a genome-wide set of gene deletions in the fission yeast Schizosaccharomyces pombe. Nat Biotechnol 28:617-623. 
646 Kimura H, Tao Y, Roeder RG, and Cook PR. 1999. Quantitation of RNA polymerase II and its

Kislauskis EH, Zhu X, and Singer RH. 1997. beta-Actin messenger RNA localization and protein synthesis augment cell motility. J Cell Biol 136:1263-1270.

Kristensen AR, Gsponer J, and Foster LJ. 2013. Protein synthesis rate is the predominant regulator of protein expression during differentiation. Mol Syst Biol 9:689.

Krutzfeldt J, Rajewsky N, Braich R, Rajeev KG, Tuschl T, Manoharan M, and Stoffel M. 2005. Silencing of microRNAs in vivo with 'antagomirs'. Nature 438:685-689.

Kuntumalla S, Braisted JC, Huang ST, Parmar PP, Clark DJ, Alami H, Zhang Q, DonohueRolfe A, Tzipori S, Fleischmann RD, Peterson SN, and Pieper R. 2009. Comparison of two label-free global quantitation methods, APEX and 2D gel electrophoresis, applied to the Shigella dysenteriae proteome. Proteome Sci 7:22.

Loriaux PM, and Hoffmann A. 2013. A protein turnover signaling motif controls the stimulussensitivity of stress response pathways. PLoS Comput Biol 9:e1002932.

Lu P, Vogel C, Wang R, Yao X, and Marcotte EM. 2007. Absolute protein expression profiling estimates the relative contributions of transcriptional and translational regulation. Nat Biotechnol 25:117-124.

Maier T, Guell M, and Serrano L. 2009. Correlation of mRNA and protein in complex biological samples. FEBS Lett 583:3966-3973.

Milo R, Jorgensen P, Moran U, Weber G, and Springer M. 2010. BioNumbers--the database of key numbers in molecular and cell biology. Nucleic Acids Res 38:D750-753.

Olkin I, and Finn JD. 1990. Testing correlated correlations. Psychological Bulletin 108:330-333.

Peng M, Taouatas N, Cappadona S, van Breukelen B, Mohammed S, Scholten A, and Heck AJ. 2012. Protease bias in absolute protein quantitation. Nat Methods 9:524-525.

Pillai RS, Bhattacharyya SN, and Filipowicz W. 2007. Repression of protein synthesis by miRNAs: how many mechanisms? Trends Cell Biol 17:118-126.

Princiotta MF, Finzi D, Qian SB, Gibbs J, Schuchmann S, Buttgereit F, Bennink JR, and Yewdell JW. 2003. Quantitating protein synthesis, degradation, and endogenous antigen processing. Immunity 18:343-354.

Rabani M, Levin JZ, Fan L, Adiconis X, Raychowdhury R, Garber M, Gnirke A, Nusbaum C, Hacohen N, Friedman N, Amit I, and Regev A. 2011. Metabolic labeling of RNA uncovers principles of RNA production and degradation dynamics in mammalian cells. Nat Biotechnol 29:436-442.

Rajewsky N. 2011. MicroRNAs and the Operon paper. J Mol Biol 409:70-75. 
681 Schwanhausser B, Busse D, Li N, Dittmar G, Schuchhardt J, Wolf J, Chen W, and Selbach M. 2011. Global quantification of mammalian gene expression control. Nature 473:337342.

Selbach M, Schwanhausser B, Thierfelder N, Fang Z, Khanin R, and Rajewsky N. 2008. Widespread changes in protein synthesis induced by microRNAs. Nature 455:58-63.

Sharova LV, Sharov AA, Nedorezov T, Piao Y, Shaik N, and Ko MS. 2009. Database for mRNA half-life of 19977 genes obtained by DNA microarray analysis of pluripotent and differentiating mouse embryonic stem cells. DNA Res 16:45-58.

Subtelny AO, Eichhorn SW, Chen GR, Sive H, and Bartel DP. 2013. Poly(A)-tail lengths and a developmental switch in translational control. Nature in press.

Vogel C, Abreu Rde S, Ko D, Le SY, Shapiro BA, Burns SC, Sandhu D, Boutz DR, Marcotte EM, and Penalva LO. 2010. Sequence signatures and mRNA concentration can explain two-thirds of protein abundance variation in a human cell line. Mol Syst Biol 6:400.

Vogel C, and Marcotte EM. 2012. Insights into the regulation of protein abundance from proteomic and transcriptomic analyses. Nat Rev Genet 13:227-232.

Wisniewski JR, Ostasiewicz P, Dus K, Zielinska DF, Gnad F, and Mann M. 2012. Extensive quantitative remodeling of the proteome between normal colon tissue and adenocarcinoma. Mol Syst Biol 8:611.

Wollfe A. 1998. Chromatin: Structure and Function. San Diego: Academic Press.

Wong PG, Winter SL, Zaika E, Cao TV, Oguz U, Koomen JM, Hamlin JL, and Alexandrow MG. 2011. Cdc45 limits replicon usage from a low density of preRCs in mammalian cells. PLoS One 6:e17533.

Xiao C, Calado DP, Galler G, Thai TH, Patterson HC, Wang J, Rajewsky N, Bender TP, and Rajewsky K. 2007. MiR-150 controls B cell differentiation by targeting the transcription factor c-Myb. Cell 131:146-159.

Yang E, van Nimwegen E, Zavolan M, Rajewsky N, Schroeder M, Magnasco M, and Darnell JE, Jr. 2003. Decay rates of human mRNAs: correlation with functional characteristics and sequence attributes. Genome Res 13:1863-1872.

Zeiler M, Straube WL, Lundberg E, Uhlen M, and Mann M. 2012. A Protein Epitope Signature Tag (PrEST) library allows SILAC-based absolute quantification and multiplexed

713 


\section{Table 1 (on next page)}

The contribution of different steps in gene expression to the variance in protein abundances between genes.

* In this column, the value given for Schwanhausser et al.'s $2^{\text {nd }}$ data is the variance in their measured protein abundances; the remaining values are our estimate for the variance in true protein levels for different scenarios.

a Estimates from Schwanhausser et al. based on the 4,212 genes for which NIH3T3 cell protein and mRNA abundance data are available.

b Our estimates for same the 4,212 genes studied by Schwanhausser et al. after correcting the overall scaling of the NIH3T3 cell protein abundance data and taking molecule specific stochastic and systematic experimental error into account.

c Our estimates for same the 4,212 genes studied by Schwanhausser et al. derived using measured translation rates from Subtelny et al. 
Table 1. The contribution of different steps in gene expression to the variance in protein abundances between genes

\begin{tabular}{|c|c|c|c|c|c|c|}
\hline & \multirow{2}{*}{$\begin{array}{l}\text { variance in } \\
\text { protein } \\
\text { levels }(\log 10)\end{array}$} & \multicolumn{5}{|c|}{ Percent contribution to variance in protein levels } \\
\hline & & mRNA & Transcription & $\begin{array}{c}\text { RNA } \\
\text { degradation } \\
\end{array}$ & Translation & $\begin{array}{c}\text { Protein } \\
\text { degradation }\end{array}$ \\
\hline Schwanhausser $2^{\text {nd }}$ data $^{a}$ & 0.97 & $40 \%$ & $34 \%$ & $6 \%$ & $55 \%$ & $5 \%$ \\
\hline Measured protein error strategy ${ }^{b}$ & 0.34 & $56 \%$ & $38 \%$ & $18 \%$ & $30 \%$ & $14 \%$ \\
\hline Measured translation strategy ${ }^{c}$ & 0.61 & $81 \%$ & $71 \%$ & $10 \%$ & $11 \%$ & $8 \%$ \\
\hline
\end{tabular}




\section{Figure 1}

The steps regulating protein expression.

The steady state abundances of proteins and mRNAs are each determined by their relative rates of production (i.e. transcription or translation) and their rates of degradation.

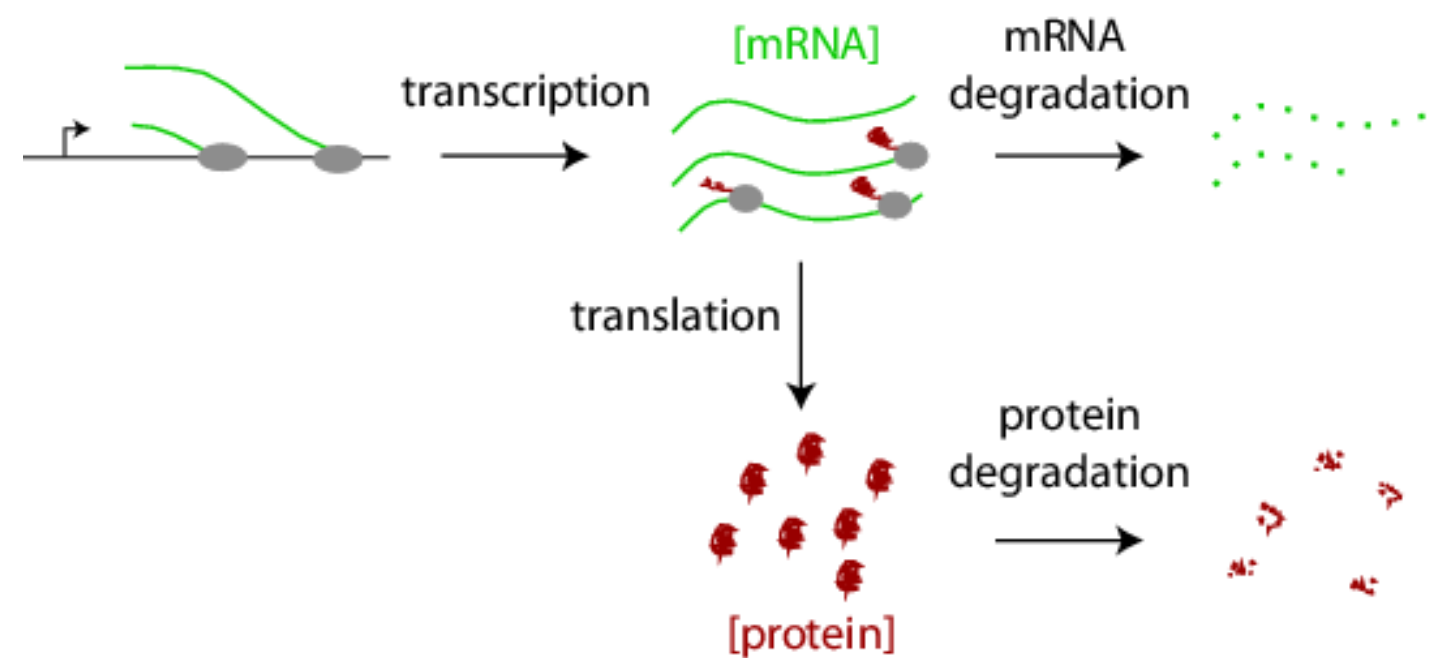




\section{Figure 2}

A non-linear bias in protein abundance estimates and its correction.

a, The $y$ axis shows the ratios of 61 individually derived protein abundance estimates divided by the abundance estimates from Schwanhausser et al.'s second whole proteome dataset.

The $x$ axis shows Schwanhausser et al.'s second whole proteome abundance estimates. The red line indicates the locally weighted line of best fit (Lowess parameter $f=1.0$ ), and the vertical dotted grey lines show the locations of the 1st quartile, median and 3rd quartile of the abundance distribution of the 5,028 proteins detected in the whole proteome analysis. $\mathbf{b}$, The same as panel a. except that the whole proteome estimates of Schwanhausser et al. have been corrected using a two-part linear model and the abundances from the 61 individual protein measurements, see Fig 4b. 
a

median

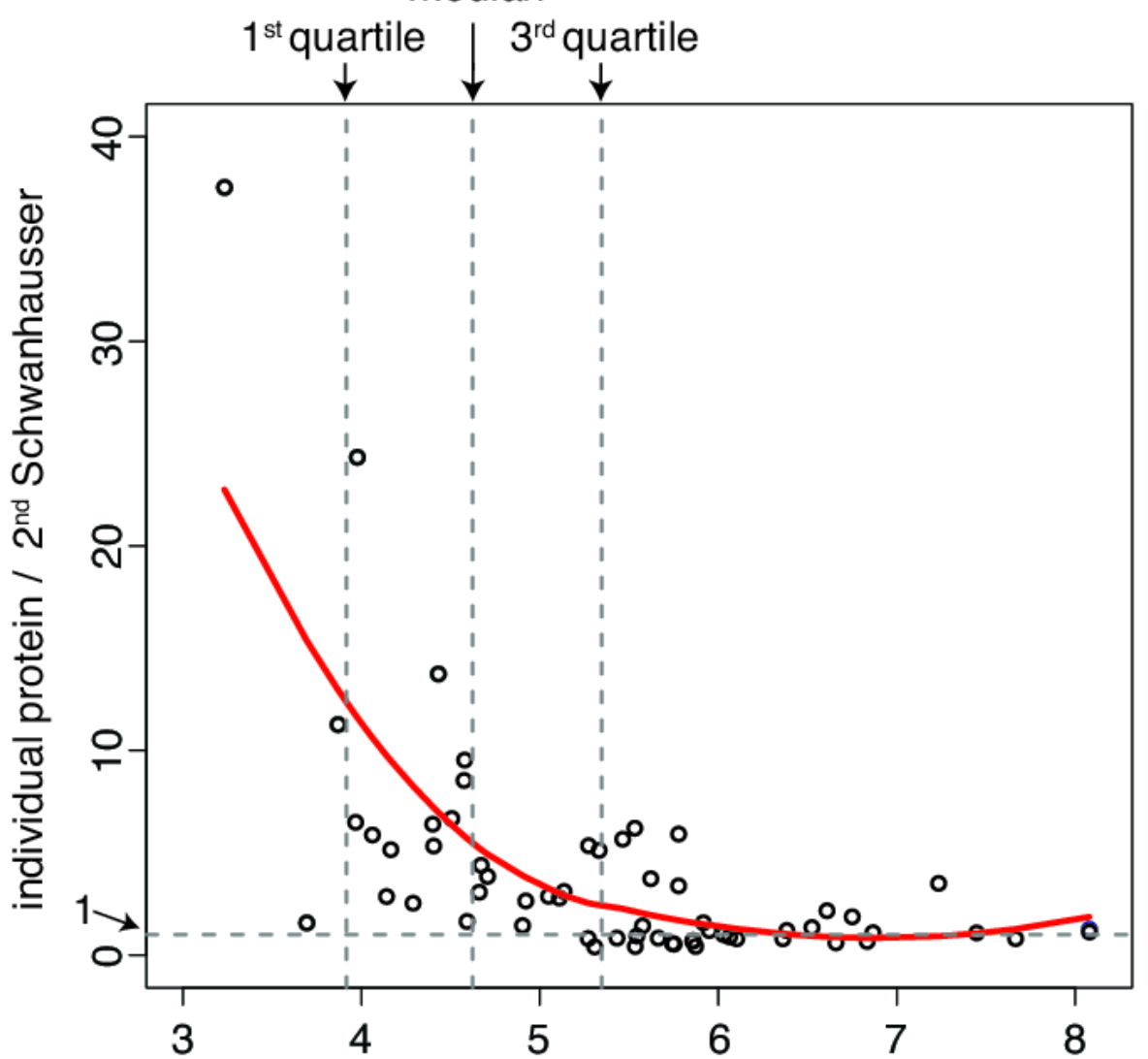

$2^{\text {nd }}$ Schwanhausser estimates: protein molecules per cell $(\log 10)$

b

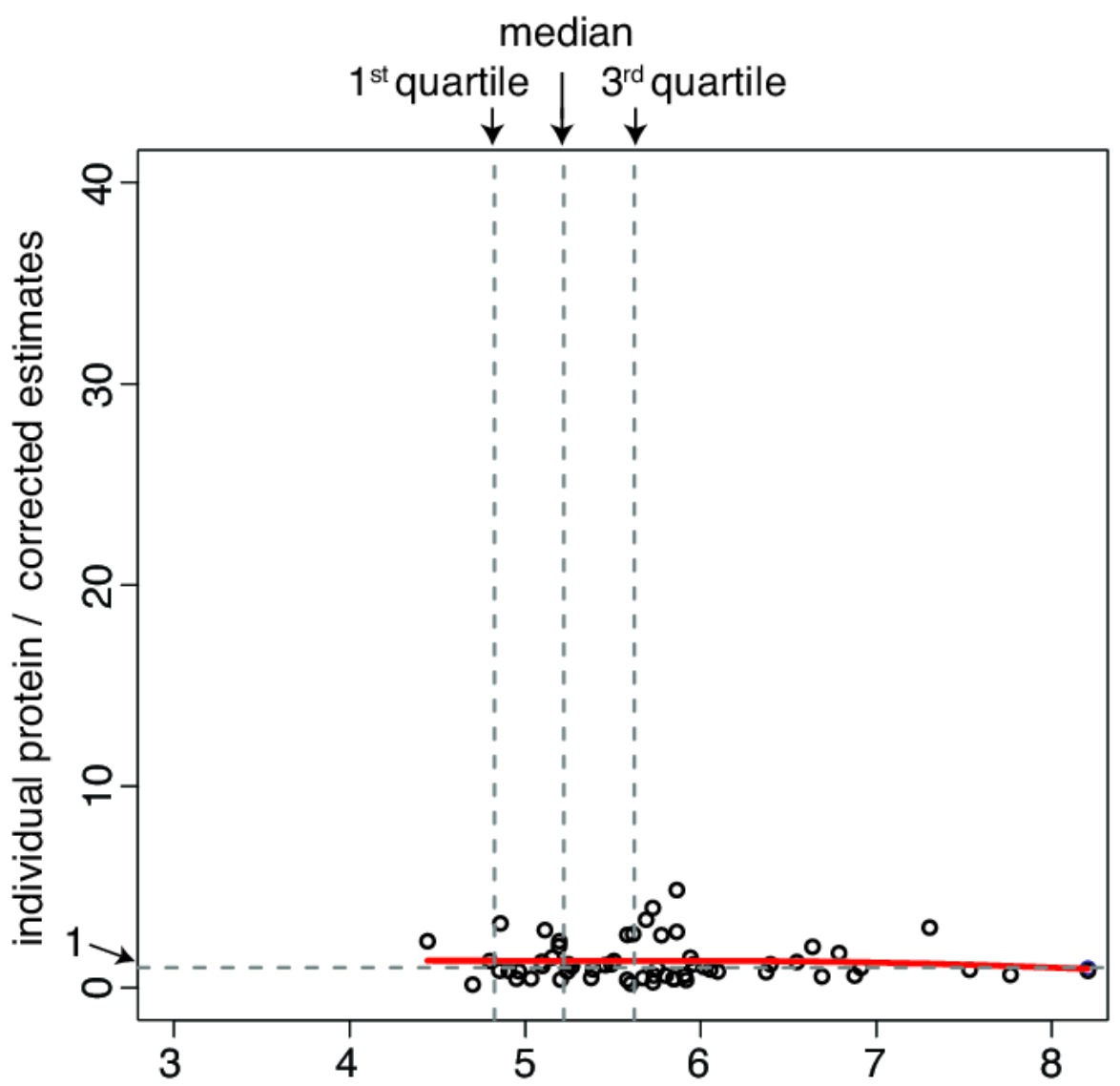




\section{Figure 3}

Calibrating absolute protein abundances.

a, The relationship between iBAC mass spectrometry signal ( $x$ axis) and the amounts of the 20 "spiked in" protein standards (y axis) used by Schwanhausser et al. to calibrate their whole proteome abundances (data kindly provided by Matthias Selbach, Dataset S2). The line of best fit is shown (red). $\mathbf{b}$, The relationship between individually derived estimates for 61 housekeeping proteins (y axis) and Schwanhausser et al.'s second whole proteome estimates ( $x$ axis). The two part line of best fit used to correct the second whole proteome estimates is shown (solid red line) as is the single linear regression (dashed red line). c, The fit of different regression models for the data in panel $b$. The $y$ axis shows the leave-one-out cross validation root mean square error for each model. The $\mathrm{x}$ axis shows the protein abundance used to separate the data for two part linear regressions. The red curve shows the optimum change point for a two part linear model is at an abundance of $\sim 10^{6}$ molecules per cell. The dashed red horizontal line shows the root mean square error for the single linear regression.
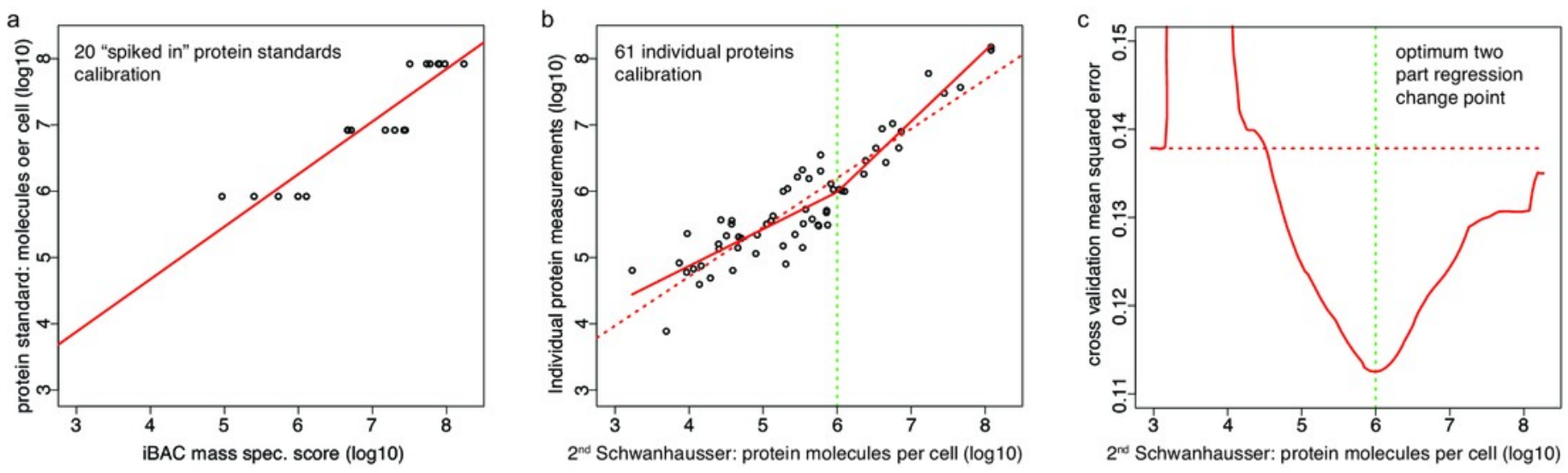


\section{Figure 4}

Protein abundance estimates versus mRNA abundances.

a, The relationship between Schwanhausser et al.'s second protein abundance estimates vs mRNA levels for 4,212 genes in NIH3T3 cells. The linear regression of the data is shown in red, the $50 \%$ prediction band by dashed green lines, and the $95 \%$ prediction band by dashed blue lines. $\mathbf{b}$, The relationship between our corrected estimates of protein abundance vs mRNA levels. The linear regression and prediction bands are labeled as in panel a. 
a

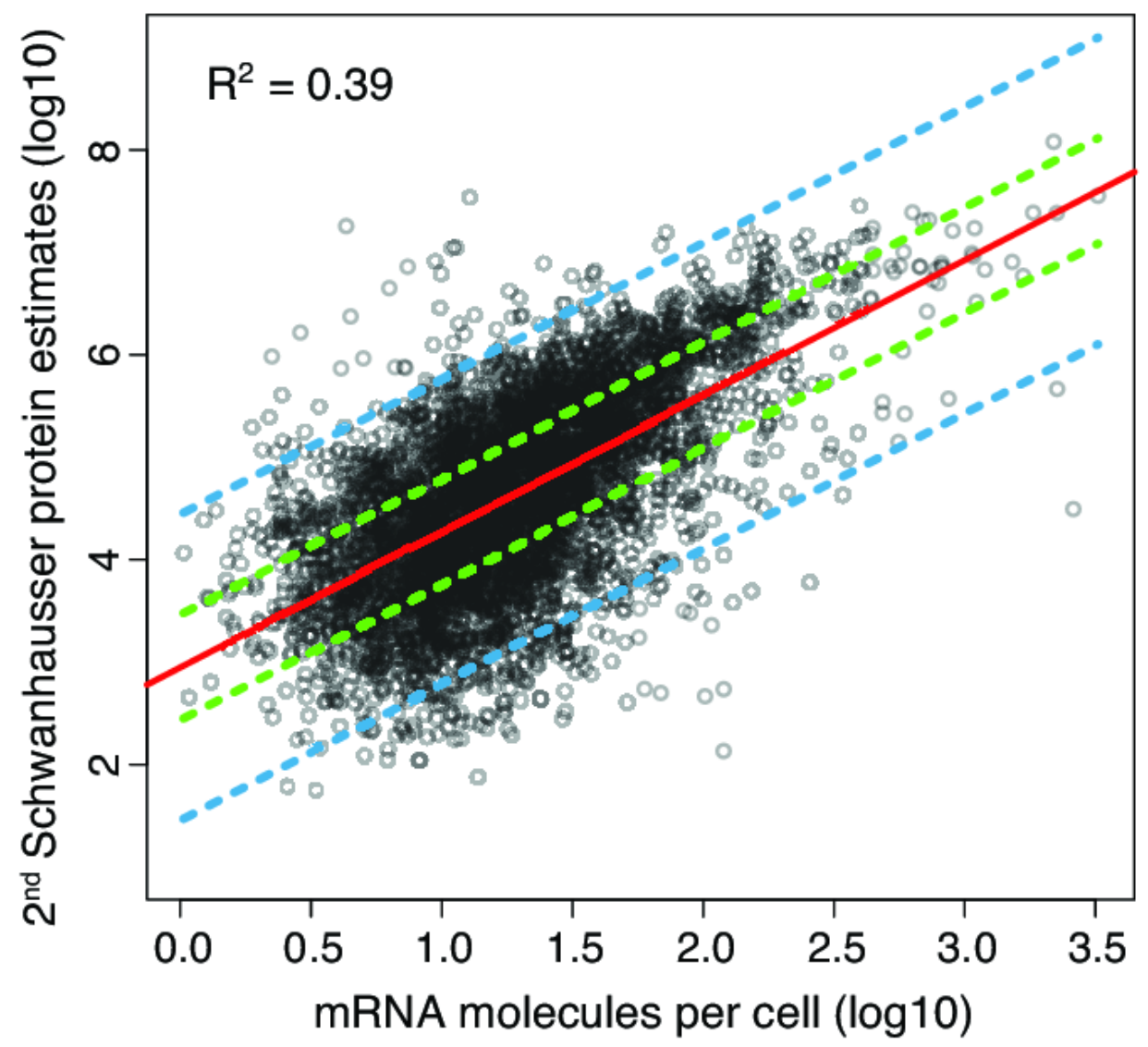

b

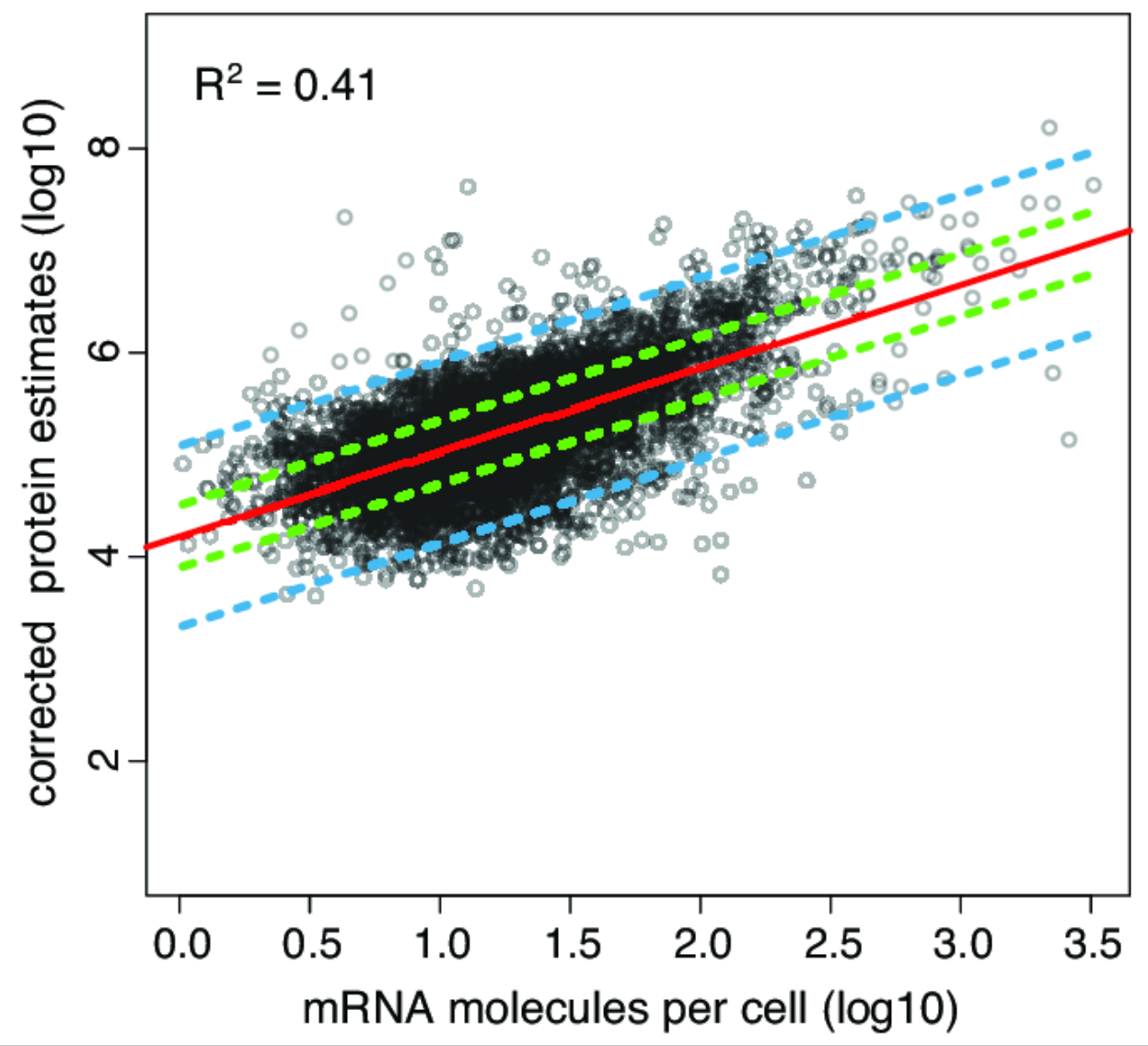




\section{Figure 5}

Measured versus inferred translation rates.

a. The relative density of ribosomes per mRNA for each gene directly measured by ribosome profiling (Guo et al. 2010; Ingolia et al. 2011; Subtelny et al. 2013) (colored lines) compared to the translation rates for each gene inferred by Schwanhausser et al. (Schwanhausser et al. 2011) (black lines). The distribution of values from the ribosome profiling experiments was scaled proportionally to have the same median as that of the Schwanhausser et al. values, and the gene frequencies of the each distribution was normalized to have the same total. The locations of the 2.5 and 97.5 percentiles of the two distributions for NIH3T3 cells are shown as dashed lines. b. As panel a. except that the data for all genes in the Schwanhausser et al. dataset are shown in the solid black line and data for the genes in the intersection of the Schwanhausser et al. and Subtelny et al.'s datasets are shown in dashed lines. The variances and numbers of genes for each dataset are given in Table S1. 

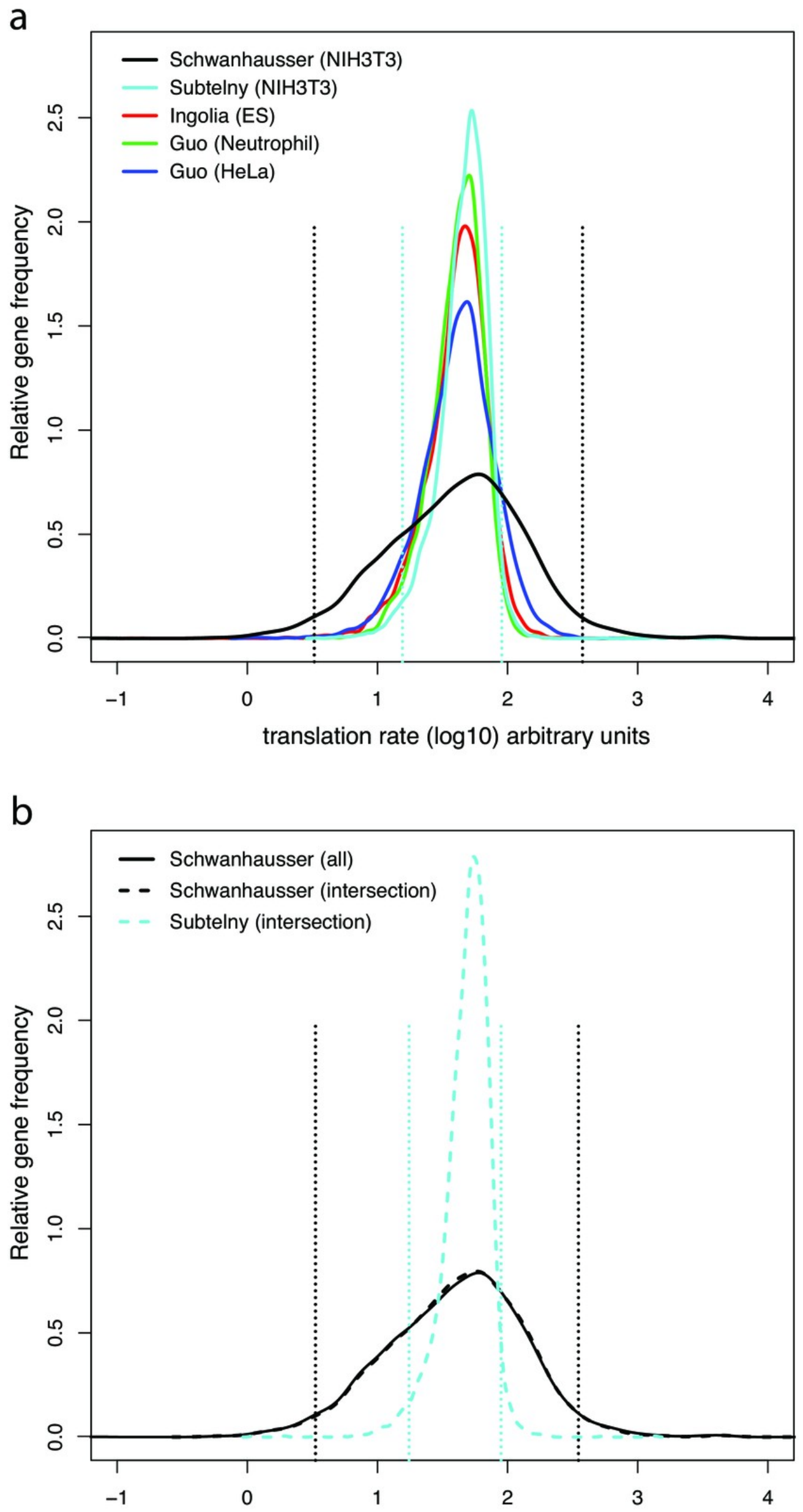

translation rate $(\log 10)$ arbitrary units
PeerJ reviewing PDF | (v2013:09:800:2:0:NEW 10 Jan 


\section{Figure 6}

Correlation between measured versus inferred translation rates.

The relationship between the measured rates of translation determined by Subtelny et al. using ribosome footprinting vs the inferred rates of translation determined by Schwanhausser et al for the same set of 3,126 genes in NIH3T3 cells, see Table S1 for further details. The units shown are those provided in the original datasets. The linear regression is shown.

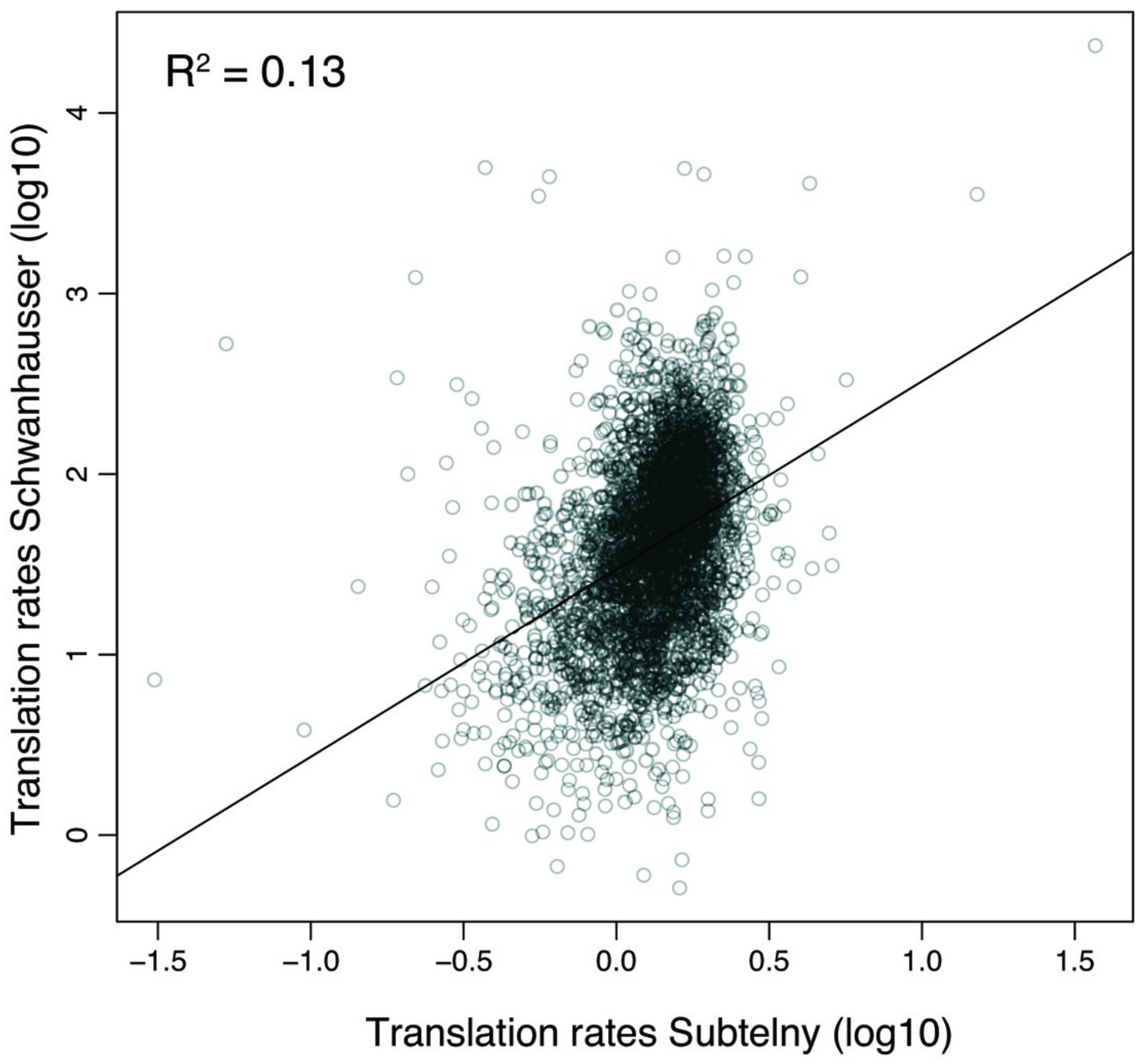




\section{Figure 7}

Comparison of corrected and uncorrected whole proteome abundance estimates.

a. The distributions of protein abundance estimates for 4,680 orthologous proteins in NIH3T3 cells (black lines) or HeLa cells (red lines). The values from Schwanhausser et al.'s second estimates and Wisniewski et al.'s estimates are shown as dashed lines. The values for our corrected abundance estimates are shown as solid lines. b. The ratios of HeLa cell whole proteome abundance estimates divided by individual measurements from the literature for 66 proteins. Results for the original data from Wisniewski et al. (dashed line) and after these values have been corrected (solid line) are plotted. The green dashed vertical line indicates a ratio of 1 . 

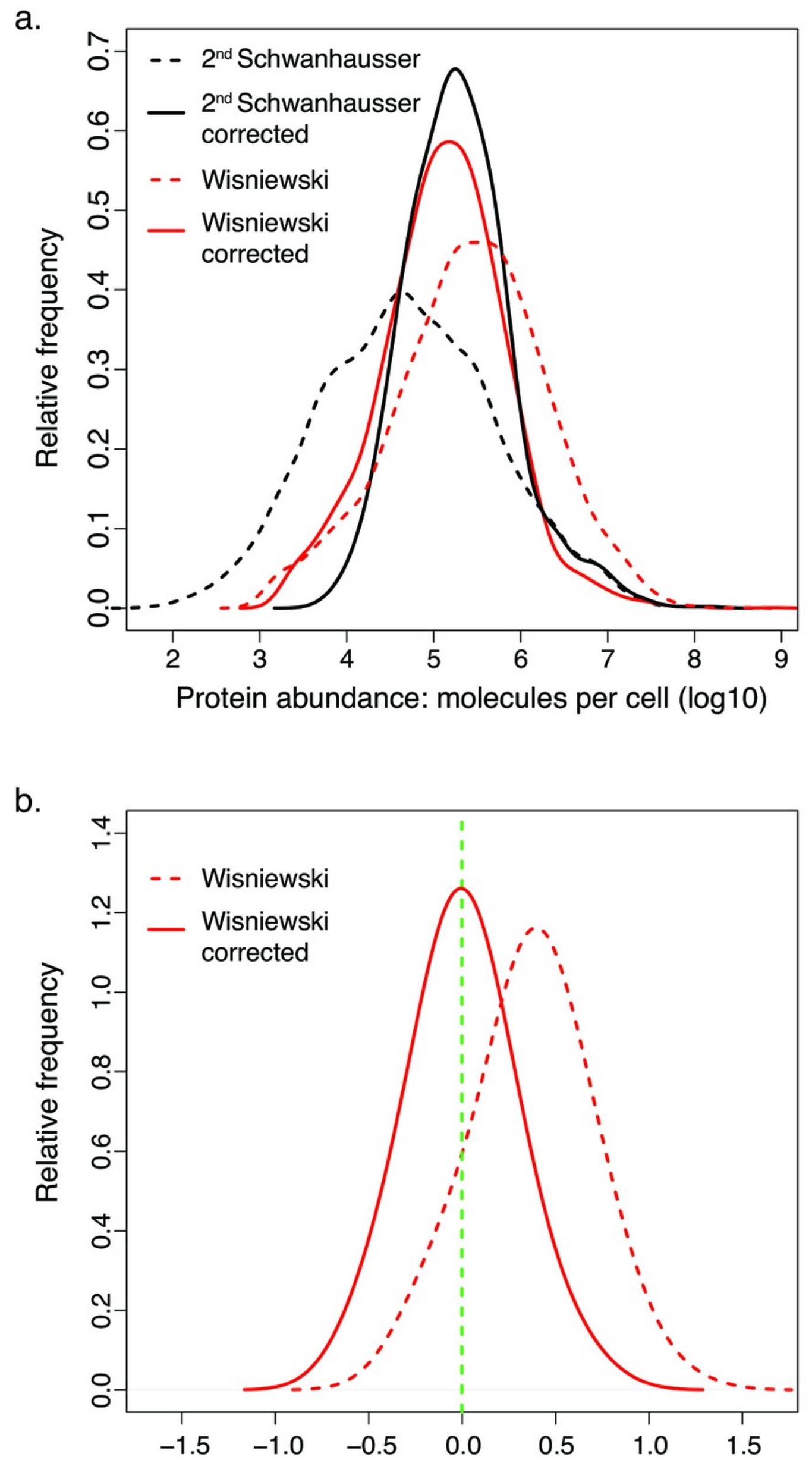

ratio whole proteome / individual abundance (log10) 


\section{Figure 8}

The relationship between true and measured protein and mRNA levels.

\section{True mRNA levels}

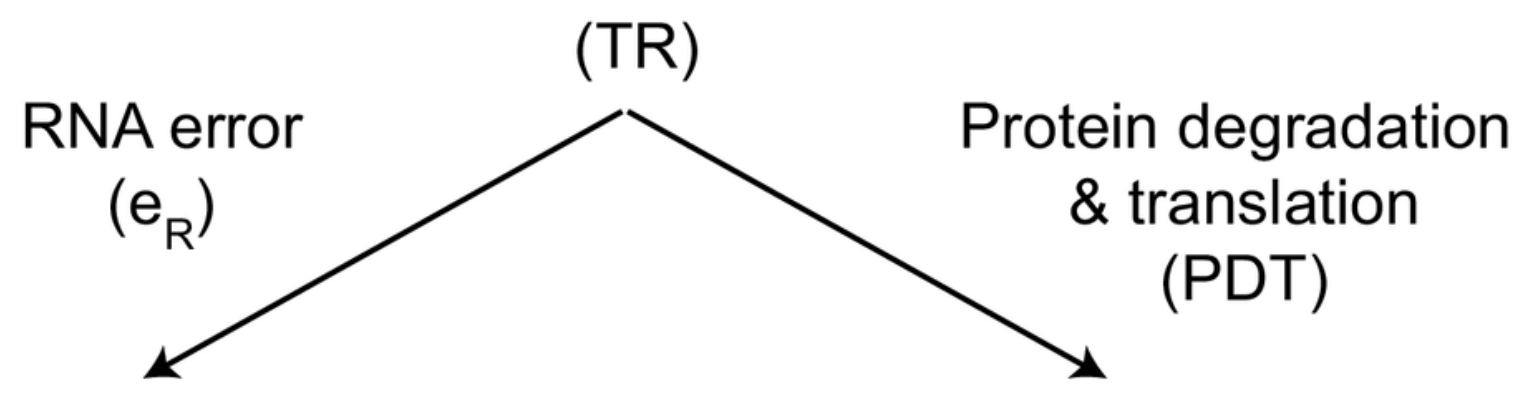

Measured mRNA levels

(MR)

True protein levels

(TP)

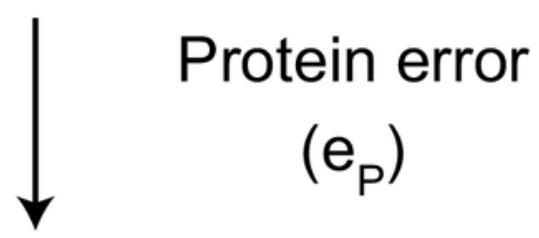

Measured protein levels

(MP) 